\title{
Field and greenhouse evaluation of spirodiclofen against Panonychus ulmi and Tetranychus urticae (Acari: Tetranychidae) in Serbia*
}

\author{
DEJAN MARCIC ${ }^{\wedge}$, SLAVKA MUTAVDZIC, IRENA MEDJO, MIRJANA PRIJOVIC \& \\ PANTELIJA PERIC \\ Institute of Pesticides and Environmental Protection, Laboratory of Applied Entomology Banatska \\ 31B, P.O. Box 163, 11080, Belgrade, Serbia; \\ 'E-mail: marcion965@gmail.com
}

* In: Moraes, G.J. de \& Proctor, H. (eds) Acarology XIII: Proceedings of the International Congress. Zoosymposia, 6, 1-304.

\begin{abstract}
Spirodiclofen, an acaricide with a novel mode of action (inhibition of lipid synthesis), has recently been commercialized and recommended as a compound that effectively controls mite populations resistant to other acaricides. The efficacy of the spirodiclofen against European red mite [Panonychus ulmi (Koch)] on apple, and two-spotted spider mite (Tetranychus urticae Koch) on greenhouse cucumber was tested in Serbia from 2004 to 2008. Spirodiclofen efficacy was compared to the effectiveness of several other acaricides (bifenthrin, clofentezine, fenazaquin, fenpyroximate) that had been in use for some time. The acaricides were applied at their recommended application rates. Control efficacy against P. ulmi was tested in a commercial apple orchard at Morovic $\left(45^{\circ} 00.711^{\prime} \mathrm{N} ; 19^{\circ} 15.146^{\prime} \mathrm{E}\right)$. Applied at the BBCH 09 growth stage (green leaf tips about $5 \mathrm{~mm}$ above bud scales) against overwintering eggs, spirodiclofen achieved 89.1 and 86.0\% efficacy in evaluations 12 and 25 DAT (days after treatment), respectively. Similar effectiveness was demonstrated for fenazaquin (91.3 and 84.4\%), while clofentezine achieved a considerably lower efficacy (67.4 and $27.8 \%$, respectively). In three trials involving the summer population of $P$. ulmi in three vegetation seasons, spirodiclofen achieved high and steady efficacy: $91 \%$ (15 DAT), $97.2 \%$ (30 DAT) and 98\% (45 DAT) in the first season; $95.2 \%$ (14 DAT), $96.3 \%$ (29 DAT) and 95.7\% (47 DAT) in the second season; and 97.4\% (14 DAT), 95.6\% (21 DAT) and 97\% (38 DAT) in the third season. The highest clofentezine efficacy in the first season was 90.9\% (30 DAT), 77.4\% (29 DAT) in the second and $68.1 \%$ (21 DAT) in the third season. Bifenthrin achieved the highest efficacy in the first season, $78.2 \%$ (15 DAT), while it declined to $65.9 \%$ (14 DAT) in the second and was practically negligible in the third season. Such unsatisfactory efficacies of bifenthrin and clofentezine were probably the result of resistance development under selection pressure of these compounds at Morovic. The efficacy of fenpyroximate, tested in the second season, was high $(97.4 \%)$ in evaluations 14 and 29 DAT, but it was only 50.3\% in evaluation 47 DAT. Efficacy in controlling T. urticae was tested in a

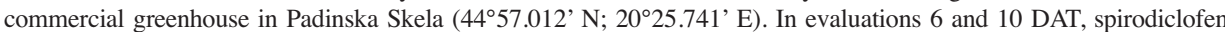
achieved 98.4 and $96.8 \%$ efficacy, while clofentezine effectiveness was 95.4 and $93.4 \%$, and bifenthrin efficacy 96.5 and $98.8 \%$, respectively. The results showed that spirodiclofen is effective in controlling European red mite on apple and twospotted spider mite on cucumber, and a good alternative to older acaricides.
\end{abstract}

Key words: spirodiclofen, Panonychus ulmi, Tetranychus urticae, chemical control.

\section{Introduction}

Spider mite (Acari: Tetranychidae) resistance to acaricides has become a global phenomenon as a result of their exceptional intrinsic potential to evolve resistance and human activities contributing to it. A way of dealing with the resistance is to search for new compounds acting on novel biochemical and physiological targets (Dekeyser, 2005; Whalon et al., 2008; van Leeuwen et al., 2009). Spirodiclofen, a tetronic acid derivative, is the first member of a class of acaricides/insecticides with new mode of action - inhibition of lipid biosynthesis. This compound exhibits activity against eggs and immatures of spider mites, while its activity against adult females is slower, with strong reduction of fecundity and fertility (Wachendorff et al., 2002; 
Bretschneider et al., 2007; Marcic, 2007; van Pottelberge et al., 2009). Spirodiclofen has been commercialized for worldwide use against all important phytophagous mites in perennial and row crops (Elbert et al., 2002; Bretschneider et al., 2007). Owing to its new mode of action, spirodiclofen is characterized by lack of cross-resistance to any other commercial acaricide, and is recommended as an effective option for controlling resistant mite populations (Dekeyser, 2005; Bretschneider et al., 2007).

This paper presents the results of tests on the efficacy of spirodiclofen against European red mite [Panonychus ulmi (Koch)] on apple and two-spotted spider mite (Tetranychus urticae Koch) on greenhouse cucumber, carried out in Serbia. The efficacy of spirodiclofen was compared to other acaricides already in use and the results are discussed with a view to improving the control of P. ulmi and T. urticae populations.

\section{Materials and Methods}

Biological efficacy of spirodiclofen (commercial product Envidor ${ }^{\circledR}, 240 \mathrm{~g} / \mathrm{L}$ a.i., Bayer CropScience) and five other acaricides used for spider mite control was tested in four field trials $(\mathrm{F} 1-\mathrm{F} 4)$ and one greenhouse trial $(\mathrm{GH})$ (Tables 1,2). The trials were conducted in four replications in a randomized block design. The acaricides were applied at their recommended rates by a Stihl portable spraying device until run-off.

Biological efficacy against $P$. ulmi on apple was tested in a commercial orchard at Morović locality $\left(45^{\circ} 00.711^{\prime} \mathrm{N} ; 1^{\circ} 15.146^{\prime} \mathrm{E}\right)$, in plots of five trees. The efficacy against overwintering eggs of $P$. ulmi was investigated in trial F1. The acaricides were applied at the BBCH 09 growth stage (green leaf tips about $5 \mathrm{~mm}$ above bud scales) (Meier, 2001). Daily inspections of overwintering eggs in untreated plots showed that the treatment was applied five days before larval development. Motile forms of P. ulmi were counted on 50 young leaves per plot 12 days and 25 days after treatment. The efficacy against summer population was investigated in trials F2-F4. Motile forms were counted on 25 leaves per plot before treatment and three times after treatment.

The efficacy against $T$. urticae on cucumber was tested in a commercial greenhouse (trial GH) at Padinska Skela locality (44⒌ $57.012^{\prime}$ N; $20^{\circ} 25.741^{\prime}$ E) in plots of 10 plants. Motile forms were counted on ten leaves per plot (one whole leaf per plant) before treatment and twice after treatment.

TABLE 1. Field (F1-F4) and greenhouse (GH) trials against spider mites conducted in Serbia.

\begin{tabular}{lccccc}
\hline Pest & Trial & Date & Locality & Crop & Cultivar \\
\hline Panonychus ulmi & F1 & $2004,4 / 16-5 / 11$ & Morović & Apple & Red Chief \\
& F2 & $2004,7 / 19-9 / 3$ & Morović & Apple & Granny Smith \\
& F3 & $2005,7 / 27-11 / 12$ & Morović & Apple & Granny Smith \\
& F4 & $2008,6 / 27-8 / 4$ & Morović & Apple & Red Chief \\
Tetranychus urticae & GH & $2008,8 / 12-8 / 23$ & Padinska Skela & Cucumber & Caman \\
\hline
\end{tabular}

TABLE 2. Pesticides applied in field (F1-F4) and greenhouse (GH) trials in Serbia.

\begin{tabular}{lllc}
\hline Products & \multicolumn{1}{c}{ Active ingredients } & \multicolumn{1}{c}{ Manufacturers } & Trials \\
\hline Talstar 10-EC & Bifenthrin $\left(100 \mathrm{~g} \mathrm{~L}^{-1}\right)$ & FMC International S.A., USA & F2, F3, \\
Fobos EW & Bifenthrin $\left(100 \mathrm{~g} \mathrm{~L}^{-1}\right)$ & Galenika-Fitofarmacija, Serbia & F4, GH \\
Apollo 50-SC & Clofentezine $\left(500 \mathrm{~g} \mathrm{~L}^{-1}\right)$ & Makhteshim Chemical Works, Israel & F1, F2, F3, F4,GH \\
Ortus 5-SC & Fenpyroximate $\left(50 \mathrm{~g} \mathrm{~L}^{-1}\right)$ & Nihon Nohyaku, Japan & F3 \\
Demitan 200-SC & Fenazaquin $\left(200 \mathrm{~g} \mathrm{~L}^{-1}\right)$ & Margarita International, Portugal & F1 \\
Envidor & Spirodiclofen $\left(240 \mathrm{~g} \mathrm{~L}^{-1}\right)$ & Bayer CropScience, Germany & F1, F2, F3, F4, GH \\
\hline
\end{tabular}


The numbers of motile forms of mites per plot were subjected to ANOVA and significant differences in means were identified by Tukey's tests. The data were transformed by $\sqrt{X+0.5}$ before analysis. The efficacy of acaricides was calculated by Abbott's formula (1) in trial F1, and by Henderson-Tilton's formula (2) in trials F2-F4 and GH.

(1) $\quad E f \%=\left(1-N_{t} / N_{c}\right) \times 100$

$N=$ the number of motile forms per plot

$t=$ treated plots

$c=$ control plots

(2)

$$
\begin{aligned}
& E \boldsymbol{E} \%=\left[1-\left(N_{t a} / N_{c a}\right)\left(N_{c b} / N_{t b}\right)\right] \times \mathbf{1 0 0} \\
& N=\text { the number of motile forms per plot } \\
& t=\text { treated plots } \\
& c=\text { control plots } \\
& a=\text { after treatment } \\
& b=\text { before treatment }
\end{aligned}
$$

\section{Results and Discussion}

Application of spirodiclofen (Envidor ${ }^{\circledR}$ ) on overwintering P. ulmi eggs resulted in 89.1 and $86 \%$ efficacy in evaluations 12 and 25 days after treatment (DAT) (Table 3). Biological profile of spirodiclofen shows excellent activity against eggs and other immature stages of spider mites (Wachendorff et al., 2002; Bretschneider et al., 2007). Wachendorff et al. (2002) reported that spirodiclofen was more effective against mixed population of $P . u l m i$ at $30^{\circ} \mathrm{C}$ than at $20^{\circ} \mathrm{C}$, indicating a positive temperature coefficient. Our results indicate that spirodiclofen can be very effective even at relatively low temperatures (average daily temperature of $12^{\circ} \mathrm{C}$ ). This effect of spirodiclofen is the result of its pronounced residual effect and good rain stability (Wachendorff et al., 2002). Biological efficacy of two other acaricides used for comparison was different: fenazaquin achieved efficacy close to that of spirodiclofen ( 91.3 and $84.4 \%$, respectively), while clofentezine showed a considerably lower efficacy (67.4 and 27.8\%). Such low efficacy of clofentezine, an ovo-larvicide which is recommended for application against overwintering eggs of $P$. ulmi (Aveyard et al., 1986), is probably a consequence of its long time usage at this locality.

TABLE 3. Numbers of Panonychus ulmi (means of motile forms per 25 leaves/plots) on apple 12 and 25 days after treatment (DAT) and efficacy (Ef\%) of acaricides (trial F1).

\begin{tabular}{lccccc}
\hline Acaricides & g a.i.L-1 & 12 DAT & Ef \% & 25 DAT & Ef \% \\
\hline Spirodiclofen & 0.096 & $1.5 \mathrm{c}$ & $\mathbf{8 9 . 1}$ & $3.8 \mathrm{~b}$ & $\mathbf{8 6 . 0}$ \\
Fenazaquin & 0.1 & $1.2 \mathrm{c}$ & $\mathbf{9 1 . 3}$ & $4.2 \mathrm{~b}$ & $\mathbf{8 4 . 4}$ \\
Clofentezine & 0.25 & $4.5 \mathrm{~b}$ & $\mathbf{6 7 . 4}$ & $19.5 \mathrm{a}$ & $\mathbf{2 7 . 8}$ \\
Untreated & - & $13.8 \mathrm{a}$ & - & $27.0 \mathrm{a}$ & - \\
\hline
\end{tabular}

Within a column, the means followed by different letters differ significantly (Tukey-test, $p<0.05$ ).

In three trials of efficacy against the summer population of $P$. ulmi in three vegetation seasons (Tables 4-6), spirodiclofen considerably reduced population densities, maintaining them throughout the trial at a considerably lower level than the initial density. Spirodiclofen achieved high (91-98\%) and long-lasting efficacy; in the third evaluation (38-47 DAT), the efficacy was equal to or somewhat higher than that recorded in the first evaluation (14-15 
TABLE 4. Numbers of Panonychus ulmi (means of motile forms per 25 leaves/plots) on apple before treatment (BT), 15, 30 and 45 days after treatment (DAT) and efficacy (Ef\%) of acaricides (trial F2).

\begin{tabular}{lcccccccc}
\hline Acaricides & $\mathrm{g}$ a.i. $\mathrm{L}^{-1}$ & $\mathrm{BT}$ & $15 \mathrm{DAT}$ & $\mathbf{E f} \boldsymbol{\%}$ & $30 \mathrm{DAT}$ & $\mathbf{E f} \%$ & $45 \mathrm{DAT}$ & Ef \% \\
\hline Spirodiclofen & 0.096 & $22.0 \mathrm{a}$ & $7.5 \mathrm{a}$ & $\mathbf{9 1 . 0}$ & $7.8 \mathrm{a}$ & $\mathbf{9 7 . 2}$ & $3.8 \mathrm{a}$ & $\mathbf{9 8 . 0}$ \\
Clofentezine & 0.3 & $37.2 \mathrm{a}$ & $44.2 \mathrm{~b}$ & $\mathbf{6 8 . 8}$ & $43.3 \mathrm{~b}$ & $\mathbf{9 0 . 9}$ & $127.2 \mathrm{~b}$ & $\mathbf{5 9 . 5}$ \\
Bifenthrin & 0.02 & $58.8 \mathrm{~b}$ & $48.8 \mathrm{~b}$ & $\mathbf{7 8 . 2}$ & $179.5 \mathrm{c}$ & $\mathbf{7 6 . 2}$ & $188.8 \mathrm{c}$ & $\mathbf{6 2 . 0}$ \\
Untreated & - & $26.5 \mathrm{a}$ & $101.0 \mathrm{c}$ & - & $339.5 \mathrm{~d}$ & - & $224.0 \mathrm{c}$ & - \\
\hline
\end{tabular}

Within a column, the means followed by different letters differ significantly (Tukey-test, $p<0.05$ ).

TABLE 5. Numbers of Panonychus ulmi (means of motile forms per 25 leaves/plots) on apple before treatment (BT), 14, 29 and 47 days after treatment (DAT) and efficacy (Ef\%) of acaricides (trial F3).

\begin{tabular}{lcccccccc}
\hline Acaricides & $\mathrm{g} \mathrm{a} . \mathrm{i} . \mathrm{L}^{-1}$ & $\mathrm{BT}$ & 14 DAT & $\mathbf{E f} \boldsymbol{\%}$ & $29 \mathrm{DAT}$ & $\mathbf{E f} \boldsymbol{\%}$ & 47 DAT & Ef \% \\
\hline Spirodiclofen & 0.096 & $31.8 \mathrm{a}$ & $4.5 \mathrm{a}$ & $\mathbf{9 5 . 2}$ & $3.0 \mathrm{a}$ & $\mathbf{9 6 . 3}$ & $2.8 \mathrm{a}$ & $\mathbf{9 5 . 7}$ \\
Fenpyroximate & 0.025 & $26.5 \mathrm{a}$ & $2.0 \mathrm{a}$ & $\mathbf{9 7 . 4}$ & $1.8 \mathrm{a}$ & $\mathbf{9 7 . 4}$ & $27.0 \mathrm{bc}$ & $\mathbf{5 0 . 3}$ \\
Clofentezine & 0.3 & $17.2 \mathrm{a}$ & $22.0 \mathrm{~b}$ & $\mathbf{5 6 . 8}$ & $10.0 \mathrm{~b}$ & $\mathbf{7 7 . 4}$ & $13.2 \mathrm{~b}$ & $\mathbf{6 2 . 6}$ \\
Bifenthrin & 0.02 & $24.0 \mathrm{a}$ & $24.2 \mathrm{~b}$ & $\mathbf{6 5 . 9}$ & $42.5 \mathrm{bc}$ & $\mathbf{3 1 . 1}$ & $56.8 \mathrm{c}$ & $\mathbf{0 . 0}$ \\
Untreated & - & $23.8 \mathrm{a}$ & $70.5 \mathrm{c}$ & - & $61.2 \mathrm{c}$ & - & $48.8 \mathrm{c}$ & - \\
\hline
\end{tabular}

Within a column, the means followed by different letters differ significantly (Tukey-test, $p<0.05$ ).

TABLE 6. Number of $P$. ulmi $^{1)}$ on apple before treatment (BT), 14, 21 and 38 days after treatment (DAT) and efficacy (Ef\%) of acaricides (trial F4).

\begin{tabular}{lcccccccc}
\hline Acaricides & g a.i. $\mathrm{L}^{-1}$ & $\mathrm{BT}$ & $14 \mathrm{DAT}$ & $\mathbf{E f} \boldsymbol{\%}$ & $21 \mathrm{DAT}$ & $\mathbf{E f} \boldsymbol{\%}$ & $38 \mathrm{DAT}$ & Ef \% \\
\hline Spirodiclofen & 0.096 & $52.5 \mathrm{a}$ & $4.8 \mathrm{a}$ & $\mathbf{9 7 . 4}$ & $5.0 \mathrm{a}$ & $\mathbf{9 5 . 6}$ & $0.8 \mathrm{a}$ & $\mathbf{9 7 . 0}$ \\
Clofentezine & 0.3 & $42.2 \mathrm{a}$ & $75.0 \mathrm{~b}$ & $\mathbf{4 8 . 9}$ & $29.2 \mathrm{~b}$ & $\mathbf{6 8 . 1}$ & $13.0 \mathrm{~b}$ & $\mathbf{3 8 . 9}$ \\
Bifenthrin & 0.02 & $47.5 \mathrm{a}$ & $193.0 \mathrm{c}$ & $\mathbf{0 . 0}$ & $126.0 \mathrm{c}$ & $\mathbf{0 . 0}$ & $87.0 \mathrm{c}$ & $\mathbf{0 . 0}$ \\
Untreated & - & $65.5 \mathrm{a}$ & $228.0 \mathrm{c}$ & - & $142.0 \mathrm{c}$ & - & $33.0 \mathrm{~b}$ & - \\
\hline
\end{tabular}

1) mean number of motile forms per 25 leaves/plot

Within a column, the means followed by different letters differ significantly (Tukey-test, $p<0.05$ ).

DAT). In all three seasons, the acaricide was applied before an approximate damage threshold of five motile forms per leaf was reached. In trials carried out in several EU countries, spirodiclofen showed efficacy higher than 90\% 26-32 DAT, when applied at the recommended concentration (0.096 g a.i. $\left.\mathrm{L}^{-1}\right)$ against summer population of $P$. ulmi on apple trees at low to medium initial infestation (Elbert et al., 2002).

Clofentezine and bifenthrin showed unsatisfactory efficacy in the first season; in the next two seasons, their efficacy dropped to the level that practically made them useless against $P$. ulmi at the Morovic locality. This situation was probably the result of intense selection pressure on populations in the previous years. Use of clofentezine had been stopped before our first trial, while bifenthrin (and other pyrethroids) are still occasionally used against other pests. Although the resistance of this population still needs to be investigated, it is evident that spirodiclofen, an acaricide with a novel mode of action, is an excellent option to control P. ulmi at localities characterized by significantly reduced efficacy of other acaricides. In the second season trials, fenpyroximate demonstrated high efficacy (97.4\%) in two initial evaluations, but in the third (47 DAT), its efficacy was almost twice lower. As an inhibitor of respiration, fenpyroximate can be used as an alternative to clofentezine and bifenthrin, although its activity is shorter in comparison to spirodiclofen. The rotation of a large number of acaricides with different mode of action is essential for implementation of an effective acaricide resistance management program (Wege \& Leonard, 1994), as it extends the usage time of available acaricides and ensures effective control of European red mite in apple orchards. 
Efficacy testing of spirodiclofen against $T$. urticae on greenhouse cucumber showed high effectiveness of this acaricide (Table 7). In evaluations 6 DAT and 10 DAT, spirodiclofen achieved 98.4 and $96.8 \%$ efficacy, while the efficacy of clofentezine was 95.4 and $93.4 \%$, and efficacy of bifenthrin was 96.5 and $98.8 \%$, respectively. Spirodiclofen is not registered for use against phytophagous mites on cucumber or any other greenhouse vegetable. As a highly polyphagous and cosmopolitan species, two-spotted spider mite is a common pest of greenhouse crops worldwide. The effective control of these populations is limited primarily by their extreme capability to develop acaricide resistance in a short time (van Leeuwen et al., 2009). Therefore, it is very important to expand the biochemical diversity of acaricides used against $T$. urticae by including spirodiclofen.

TABLE 7. Number of T. uticae ${ }^{1)}$ on cucumber before treatment (BT), 6 and 10 days after treatment (DAT) and efficacy (Ef \%) of acaricides (greenhouse trial).

\begin{tabular}{|c|c|c|c|c|c|c|}
\hline Acaricides & g a.i.L-1 & BT & 6 DAT & Ef\% & $10 \mathrm{DAT}$ & Ef\% \\
\hline Spirodiclofen & 0.096 & $14.4 \mathrm{a}$ & $0.2 \mathrm{a}$ & 98.4 & $0.3 \mathrm{a}$ & 96.8 \\
\hline Clofentezine & 0.3 & $28.2 \mathrm{ab}$ & $1.1 \mathrm{a}$ & 95.4 & $1.2 \mathrm{a}$ & 93.4 \\
\hline Bifenthrin & 0.05 & $26.9 \mathrm{ab}$ & $0.8 \mathrm{a}$ & 96.5 & $0.2 \mathrm{a}$ & 98.8 \\
\hline$\underline{\text { Untreated }}$ & - & $21.4 \mathrm{ab}$ & $18.1 \mathrm{~b}$ & - & $13.8 \mathrm{~b}$ & - \\
\hline
\end{tabular}

1) mean number of motile forms per leaf (1 whole leaf per plant, 10 plants per plot)

Within a column, the means followed by different letters differ significantly (Tukey-test, $p<0.05$ ).

The results proved spirodiclofen to be effective in controlling European red mite on apple and two-spotted spider mite on cucumber, and a good alternative to older acaricides. The best application timing for this product is at the beginning of infestation and only one treatment per season or cropping cycle is recommended, in order to prevent or delay resistance development (Wachendorff et al., 2002; Elbert et al., 2002).

\section{Acknowledgment}

This study was carried out as a part of Project TR 31043 which is financially supported by the Ministry of Education and Science of the Republic of Serbia.

\section{References}

Aveyard, C.S., Peregrine, D.J. \& Bryan, K.M.G. (1986) Biological activity of clofentezine against eggs and motile stages of tetranychid mites. Experimental and Applied Acarology, 2, 223-229.

Bretschneider, T., Fischer, R. \& Nauen, R. (2007) Inhibitors of lipid synthesis. In: Krämer, W. \& Schirmer, U. (eds) Modern crop protection compounds, Vol. 3. Wiley-VCH Verlag GmbH \& Co, Weinheim, pp. 909-925.

Dekeyser, M.A. (2005) Acaricide mode of action. Pest Management Science, 61, 103-110.

Elbert, A., Brück, E., Sone, S. \& Toledo, A. (2002) Worldwide use of the new acaricide Envidor ${ }^{\circledR}$ in perennial crops. Pflanzenschutz-Nachrichten Bayer, 55, 287-304.

Marcic, D. (2007) Sublethal effects of spirodiclofen on life history and life-table parameters of two-spotted spider mite (Tetranychus urticae). Experimental and Applied Acarology, 42, 121-129.

Meier, U. (2001) Growth Stages of mono and dicotyledonous plants, BBCH Monograph, $2^{\text {nd }}$ edition. Federal Biological Research Centre for Agriculture and Forestry, Berlin and Braunschweig.

Van Leeuwen, T., Vontas, J., Tsagkarakou, A. \& Tirry, L. (2009) Mechanisms of acaricide resistance in the twospotted spider mite Tetranychus urticae. In: Ishaaya, I. \& Horowitz, A.R. (eds) Biorational control of arthropod pests. Springer, Dordrecht, pp. 347-393.

Van Pottelberge, S., Khajehali, J., van Leeuwen, T. \& Tirry, L. (2009) Effects of spirodiclofen on reproduction in a susceptible and resistant strain of Tetranychus urticae (Acari: Tetranychidae). Experimental and Applied Acarology, 47, 301-309. 
Wachendorff, U., Nauen, R., Schnorbach, H.J., Rauch, N. \& Elbert, A. (2002) The biological profile of spirodiclofen $\left(\right.$ Envidor $^{\circledR}$ ) - a new selective tetronic acid acaricide. Pflanzenschutz-Nachrichten Bayer, 55, 149-176.

Wege, P.J. \& Leonard, P.K. (1994) Insecticide Resistance Action Committee (IRAC) fruit crops spider mite resistance management guidelines. In: Proceedings of the Brighton Crop Protection Conference - Pests \& Diseases 1994. pp. 427-430.

Whalon, M.E., Mota-Sanchez, D. \& Hollingworth, R.M. (2008) Analysis of global pesticide resistance in arthropods. In: Whalon, M.E., Mota-Sanchez, D. \& Hollingworth, R.M. (eds) Global pesticide resistance in arthropods. CABI Publishing, CAB International, Wallingford, pp. 5-31. 